\title{
Cephalosporinase and Penicillinase Activity of Gram-negative Bacteria
}

\author{
By G. A. J. AYLIFFE* \\ Department of Bacteriology, Postgraduate Medical School of London, \\ Ducane Road, London, W. 12
}

(Received 25 January 1965)

\begin{abstract}
SUMMARY
Sensitivity to ampicillin and cephalothin, the formation and induction of penicillinase and cephalosporinase, and the role of cephalosporinase in resistance to cephalothin were investigated in nine strains of Gramnegative bacteria. Naturally occurring strains resistant to cephalothin formed cephalosporinase, and ampicillin-resistant strains formed penicillinase. Cephalothin-resistant strains were all resistant to ampicillin, but the ampicillin-resistant strain of Proteus mirabilis was sensitive to cephalothin and did not form cephalosporinase. Penicillinase and cephalosporinase activity were induced by benzylpenicillin in five strains of Gram-negative bacteria and cephalosporinase was also induced by cephalothin and 6-aminopenicillanic acid in four of the inducible strains examined. Methicillin and quinacillin were variable in effect as inducers and cloxacillin partially inhibited cephalosporinase activity of two strains. Intrinsic resistance to cephalothin was high in four of five naturally occurring resistant strains.
\end{abstract}

\section{IN'TRODUCTION}

Recently isolated derivatives of cephalosporin $\mathrm{C}$, namely cephalothin (sodium salt of 7-(thiophene-2-acetamido)-cephalosporanic acid) and cephaloridine (7-[(2thienyl) acetamido]-3-(l-pyridylmethyl)-3-cephem-4-carboxylic acid betaine), show antibacterial activity against several Gram-negative bacteria. Nevertheless, many strains of Gram-negative bacteria are resistant to these antibiotics and form an enzyme which inactivates cephalosporin (Chauvette et al. 1962; Fleming, Goldner \& Glass, 1963; Barber \& Waterworth, 1964; Muggleton, O'Callaghan \& Stevens, 1964). It has been shown that ampicillin resistance can usually be correlated with penicillinase formation, although most ampicillin-resistant strains of Gram-negative bacteria also show some degree of intrinsic resistance (Ayliffe 1963; Percival, Brumfitt $\&$ de Louvois, 1963; Sutherland, 1964). Ampicillin is readily inactivated, as is benzylpenicillin, by the penicillinases of Staphylococcus aureus and Bacillus cereus (Smith \& Hamilton-Miller, 1963), whereas cephalosporin $\mathrm{C}$ is inactivated slowly by these enzymes (Crompton et al. 1962). It was thought of interest to determine the sensitivity to ampicillin and cephalothin of some Gram-negative bacteria of clinicalimportance and to compare penicillinase and cephalosporinase activity and induction in these strains. The role of cephalosporinase in determining resistance to cephalothin was also investigated. Penicillinase and cephalosporinase activity in this paper refers to the hydrolysis of benzylpenicillin and cephalothin respectively, as assayed by an iodometric method.

\footnotetext{
* Present address: M.R.C. Hospital Infection Research Laboratory, Summerfield Hospital,
} Birmingham 18. 


\section{METHODS}

Organisms. Strains of Proteus morganii, $\boldsymbol{P}$. vulgaris, $\boldsymbol{P}$. rettgeri, $\boldsymbol{P}$. mirabilis, Klebsiella aerogenes, K. edwardsii var. edwardsii, Enterobacter (Aerobacter) aerogenes, Escherichia coli and Pseudomonas aeruginosa (pyocyanea) were used in the experiments. These strains were isolated from clinical specimens and were classified according to the tables of Cowan \& Steel (1961).

Culture media. A beef digest broth ( $\mathrm{pH} 7 \cdot 4)$ containing $0.5 \%(\mathrm{w} / \mathrm{v})$ glucose was used in all enzyme experiments. Digest broth was solidified with $1 \cdot 4 \%(\mathrm{w} / \mathrm{v})$ agar (Oxoid no. 3) for the sensitivity tests.

Minimum inhibitory concentrations. The minimum inhibitory concentrations (MIC) of cephalothin and ampicillin were determined on nutrient agar plates containing serial dilutions of the antibiotics. These plates were inoculated with a standard $4 \mathrm{~mm}$ loopful of an $18 \mathrm{hr}$ broth culture diluted 1/500 in nutrient broth (about 5000 organisms) and the lowest concentration of antibiotic which showed no growth after incubating for $18 \mathrm{hr}$ at $37^{\circ}$ was recorded as the MIC.

The effect of inoculum size on growth in cephalothin. Dilutions of $18 \mathrm{hr}$ broth cultures of 7 strains of Gram-negative bacteria were made in sets of 8 tubes containing $4.5 \mathrm{ml}$. nutrient broth and cephalothin, $0.5 \mathrm{ml}$. (about $5 \times 10^{8}$ organisms) of the broth culture was added to $4.5 \mathrm{ml}$. of nutrient broth containing cephalothin and serial tenfold dilutions were made from $1 / 10$ to $1 / 10^{8}$. The final concentration of cephalothin in each tube was $100 \mu \mathrm{g} . / \mathrm{ml}$. The cultures were incubated at $37^{\circ}$ and examined for growth at 24 and $48 \mathrm{hr}$.

Induction by benzylpenicillin. Two 6 in. $\times 1$ in. test tubes containing $9 \mathrm{ml}$. glucose broth were each inoculated with $1 \mathrm{ml}$. of an $18 \mathrm{hr}$ broth culture of the same organism and shaken for $6 \mathrm{hr}$ at $37^{\circ}$. After $2 \mathrm{hr}$ incubation, benzylpenicillin was added to one of the two cultures, in an amount such that with 7 strains the final concentration was $200 \mu \mathrm{g} . / \mathrm{ml}$., with one ampicillin-sensitive strain it was $20 \mu \mathrm{g} . / \mathrm{ml}$. and with one strain of Pseudomonas aeruginosa it was $2.0 \mathrm{mg} . / \mathrm{ml}$.

Induction by various penicillins and cephalothin. Benzylpenicillin, methicillin, cloxacillin, quinacillin, 6-aminopenicillanic acid and cephalothin were added to final concentration $200 \mu \mathrm{g} . / \mathrm{ml}$. to shaking broth cultures as described in the previous section. Whole broth cultures were used for the cephalosporinase assay.

Preparation of enzyme and assay. After incubation for $6 \mathrm{hr}$ the two broth cultures were centrifuged and the organisms resuspended in phosphate buffer $(\mathrm{pH} 6.5)$ to the same turbidity (equiv. about $5 \times 10^{9}$ bacteria $/ \mathrm{ml}$.); $5 \mathrm{ml}$. of each suspension was then treated in an M.S.E. ultrasonic disintegrator for 25 min., the tube containing the suspension was surrounded by ice to prevent any excessive rise in temperature during the sonic treatment. Penicillinase and cephalosporinase activities were estimated in the supernatant fluid, in whole organism suspensions, disintegrated organisms or whole broth cultures by an iodometric method, which assays $\beta$ lactamase and not amidase activity. Iodine is reduced by penicilloic acids and by the degradation products of cephalosporinase as soon as the $\beta$-lactam bond is ruptured; approximately 8 equivalents of iodine are equivalent to 1 mole penicilloic acid, and 4 equivalents of iodine are equivalent to 1 mole cephalosporin after hydrolysis (Fleming et al. 1963). In the assay, samples $(0.5-2.0 \mathrm{ml}$.) of enzyme preparation were added to $5 \mathrm{ml}$. substrate solution $(2.5 \mathrm{mg}$ benzylpenicillin or 
cephalothin $/ \mathrm{ml}$. in $\mathbf{0 . 2} \mathrm{M}-\mathrm{KH}_{2} \mathrm{PO}_{4}+\mathrm{Na}_{2} \mathrm{PO}_{4}$ buffer (pH 6.5) containing $50 \mu \mathrm{g}$. chloramphenicol $/ \mathrm{ml}$. to inhibit the growth of organisms in the assay where this might occur). The destruction of benzylpenicillin or cephalothin was then determined in these samples by titration against standard iodine with appropriate controls (see Perret, 1954). The tests were repeated with different broth cultures of each strain.

\section{RESULTS}

The amount of penicillinase and cephalosporinase activity in the whole organism suspensions, disintegrated organisms and supernatant fluids of cultures of several Gram-negative species grown in the presence or absence of benzylpenicillin, together with the minimum inhibitory concentrations of ampicillin and cephalothin for these organisms, are shown in Table 1. The strains examined may be divided into $\mathbf{5}$ main groups according to their response to inducer.

The strains of Proteus morganii, $P$. rettgeri, $P$. vulgaris, Enterobacter aerogenes and $P$ seudomonas aeruginosa were resistant to ampicillin and to cephalothin and formed inducible cephalosporinase and penicillinase. The cephalosporinase values were higher than the penicillinase values which were especially low in the strains of $\boldsymbol{P}$. rettgeri, $\boldsymbol{E}$. aerogenes and $\boldsymbol{P}$ s. aeruginosa. Strains of $\boldsymbol{P}$ s. aeruginosa required a much higher concentration of benzylpenicillin to demonstrate induction of cephalosporinase and penicillinase activity than was the case with the other organisms tested.

The strain of Escherichia coli was resistant to both antibiotics and formed both enzymes, but enzyme activity was not increased by growth in the presence of benzylpenicillin.

The strain of Klebsiella aerogenes was resistant to ampicillin but moderately sensitive to cephalothin. Both substrates were hydrolysed, but the cephalosporinase activity was less than the penicillinase activity; neither enzyme was inducible.

The strain of Proteus mirabilis was resistant to ampicillin and sensitive to cephalothin. Only penicillinase activity was detected; this was not increased by growth in presence of benzylpenicillin.

The strain of Klebsiella edrvardsii var. edwardsii was sensitive to ampicillin and cephalothin. Enzyme activity was low in both cases and was not induced by benzylpenicillin $20 \mu \mathrm{g} . / \mathrm{ml}$. Higher concentrations of benzylpenicillin inhibited growth in this organism.

Table 1 shows that Proteus rettgeri was the only organism which gave an appreciably higher cephalosporinase activity after cell disintegration, whereas the strains of P. mirabilis, P. morganii, Klebsiella aerogenes and Escherichia coli all showed higher penicillinase activity after disintegrating the bacteria. Both enzymes were mainly cell-bound, although moderate cephalosporinase activity was obtained in the supernatant fluid of some strains after induction. The penicillinase activity in the supernatant fluid of the strain of $K$. aerogenes was similar to that of the intact organisms, but cephalosporinase activity in the supernatant fluid was very low.

\section{Induction of cephalosporinase activity}

Table 2 shows the cephalosporinase activity of two strains of Proteus morganii and one each of $\boldsymbol{P}$. vulgaris, Enterobacter aerogenes and Klebsiella aerogenes after growth in the presence $(200 \mu \mathrm{g} . / \mathrm{ml}$.) or absence of various inducers. Growth in the 


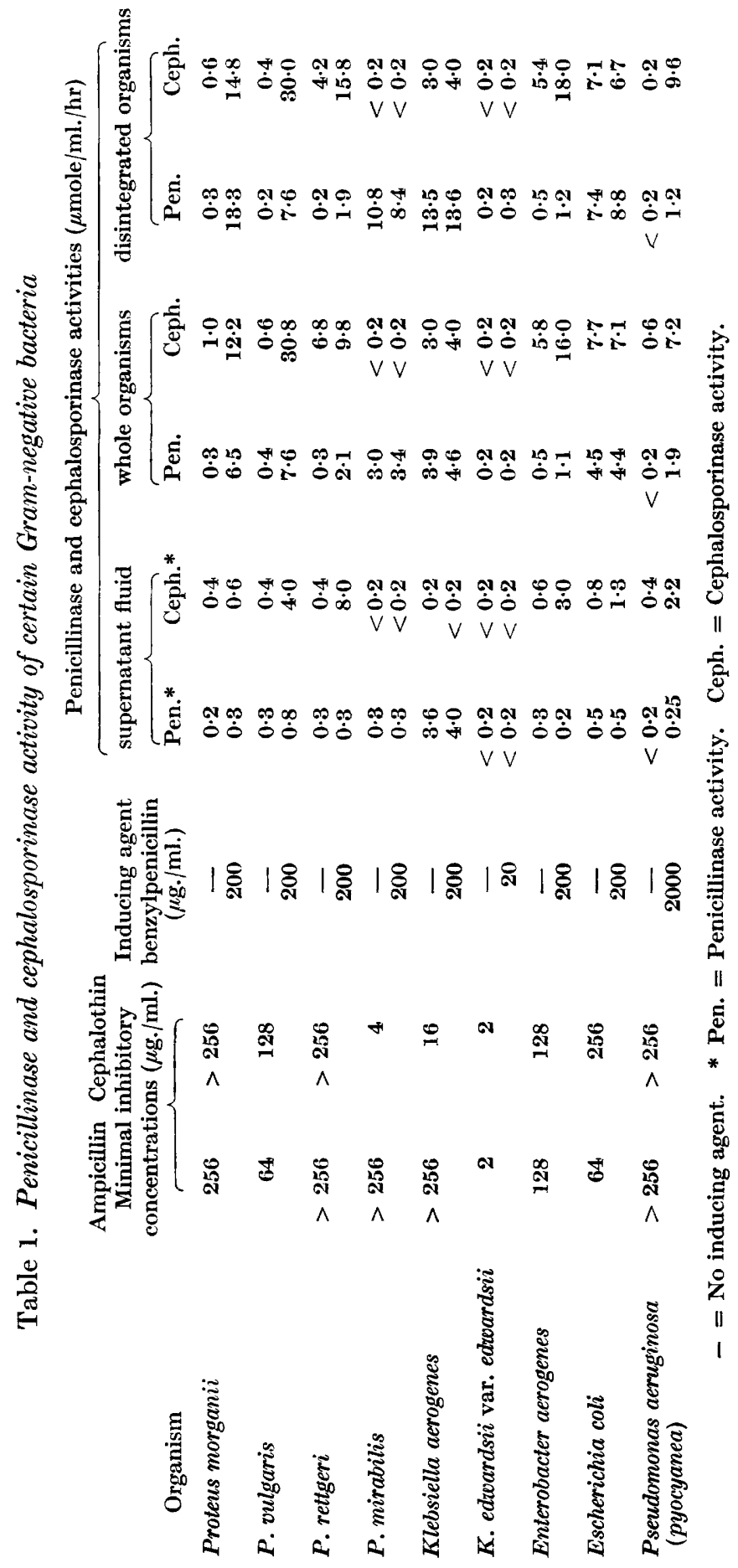


presence of benzylpenicillin, cephalothin or 6-aminopenicillanic acid led to increased cephalosporinase activity of all strains tested except $K$. aerogenes which was unaffected by any of the compounds at the concentration used. Methicillin caused a similar increase in activity with strain 1 of $\boldsymbol{P}$. morganii and the strain of $\boldsymbol{P}$. vulgaris, but not with the other organisms tested. Cloxacillin increased the activity of the same two organisms but to a lesser degree, and with strain 2 of $P$. morganii and the strain of $\boldsymbol{E}$. aerogenes the activity was apparently decreased after growth in its presence. Quinacillin increased the activity of strain 1 of $P$. morganii but did not affect that of the other organisms.

\section{Table 2. Induction of cephalosporinase}

Cephalosporinase activity ( $\mu \mathrm{mole} / \mathrm{ml}$. of broth culture/hr.) of five strains of Gramnegative bacteria after growth in the presence of six potential inducers.

\begin{tabular}{|c|c|c|c|c|c|}
\hline \multirow{2}{*}{$\begin{array}{l}\text { Inducing agent } \\
(200 \mu \mathrm{g} . / \mathrm{ml} .)\end{array}$} & Proteus & morganii & \multirow{2}{*}{ P. vulgaris } & \multirow{2}{*}{$\begin{array}{l}\text { Enterobacter } \\
\text { aerogenes }\end{array}$} & \multirow{2}{*}{$\begin{array}{l}\text { Klebsiella } \\
\text { aerogenes }\end{array}$} \\
\hline & 1 & 2 & & & \\
\hline Nil & $1 \cdot 6$ & $1 \cdot 6$ & $1 \cdot 2$ & $6 \cdot 8$ & $3 \cdot 0$ \\
\hline Benzylpenicillin & $30 \cdot 2$ & $21 \cdot 6$ & $21 \cdot 2$ & $25 \cdot 2$ & $3 \cdot 6$ \\
\hline Cephalothin & $30 \cdot 4$ & $14 \cdot 0$ & $20 \cdot 4$ & $15 \cdot 6$ & $3 \cdot 8$ \\
\hline Methicillin & $27 \cdot 6$ & $4 \cdot 8$ & $21 \cdot 6$ & $4 \cdot 0$ & $3 \cdot 4$ \\
\hline Quinacillin & $28 \cdot 0$ & $1 \cdot 6$ & $3 \cdot 6$ & $7 \cdot 2$ & $3 \cdot 8$ \\
\hline 6-A.P.A. & $26 \cdot 8$ & $19 \cdot 6$ & $14 \cdot 8$ & $30 \cdot 8$ & $4 \cdot 0$ \\
\hline Cloxacillin & $12 \cdot 8$ & $0 \cdot 8$ & $8 \cdot 8$ & $0 \cdot 8$ & $3 \cdot 6$ \\
\hline
\end{tabular}

Table 3. The effect of inoculum size on growth of certain Gram-negative bacteria in presence of cephalothin

The smallest dilution of an $18 \mathrm{hr}$ broth culture showing growth in broth containing $100 \mu \mathrm{g}$. cephalothin $/ \mathrm{ml}$.

\begin{tabular}{lccc}
\multicolumn{1}{c}{$\begin{array}{c}\text { Minimum } \\
\text { inhibitory } \\
\text { concentration } \\
\text { Organism }\end{array}$} & $\begin{array}{c}\text { Inoculum size } \\
\mu \mathrm{g} \cdot / \mathrm{mI} .\end{array}$ & $24 \mathrm{hr}$ incubation & $48 \mathrm{hr}$ incubation \\
Proteus morganii & $>256$ & $10^{-8}$ & $10^{-8}$ \\
$P$. vulgaris & 128 & $10^{-8}$ & $10^{-8}$ \\
$P$. rettgeri & $\mathbf{2 5 6}$ & $10^{-8}$ & $10^{-8}$ \\
$P$. mirabilis & 4 & $<10^{-1}$ & $<10^{-1}$ \\
Enterobacter aerogenes & 128 & $10^{-5}$ & $10^{-7}$ \\
Klebsiella aerogenes & 16 & $10^{-2}$ & $10^{-2}$ \\
Eschericha coli & 256 & $10^{-8}$ & $10^{-8}$
\end{tabular}

* Inoculum $=1 / 500$ dilution of an $18 \mathrm{hr}$ culture.

The effect of inoculum size on growth in cephalothin

The smallest inoculum of each strain which showed growth in broth containing $100 \mu \mathrm{g}$. cephalothin/ml. is shown in Table 3. With three strains of Proteus and the strain of Escherichia coli showing a minimum inhibitory concentration of $128 \mu \mathrm{g} .1$ ml. or more when tested with the standard inoculum (1/500 dilution of an $18 \mathrm{hr}$ culture), growth occurred in the presence of $100 \mu \mathrm{g} . / \mathrm{ml}$. within $24 \mathrm{hr}$ with the smallest inoculum used (about 50 organisms). The strain of Enterobacter aerogenes showed a similar degree of resistance with the standard inoculum, but the highest dilution of an $18 \mathrm{hr}$ broth culture from which an inoculum gave growth in the presence of $100 \mu \mathrm{g} . / \mathrm{ml}$. was $1 / 10^{5}$ after $24 \mathrm{hr}$ or $1 / 10^{7}$ after $48 \mathrm{hr}$. 


\section{DISCUSSION}

In this investigation, cephalosporinase and penicillinase were considered as separate enzymes but this may not be so and the results only show that Gram-negative bacteria varied in their relative hydrolytic activity against benzylpenicillin and cephalothin. Ampicillin-resistant strains showed a predominant penicillinase activity, whereas cephalothin-resistant strains predominantly hydrolysed cephalothin. Among the strains tested, ampicillin-resistant strains of Proteus mirabilis hydrolysed penicillin but not cephalothin, whereas $P$. rettgeri and Enterobacter aerogenes hydrolysed cephalothin more readily than penicillin; $P$. morganii readily hydrolysed both penicillin and cephalothin. The Gram-negative bacteria studied are examples of organisms commonly isolated from routine clinical specimens. The sensitivity to ampicillin and cephalothin is typical for most strains of Klebsiella and Enterobacter, for Pseudomonas aeruginosa and for Proteus species other than Proteus mirabilis. Strains of $\boldsymbol{P}$. mirabilis isolated in this laboratory as elsewhere were usually sensitive to ampicillin and cephalothin. A strain of Klebsiella edwardsii var. edwardsii was the only strain examined which was sensitive to both antibiotics; examples of other sensitive strains were not included as it was found that their penicillinase and cephalosporinase activities were low or non-existent.

All but one of the cephalothin-resistant organisms grew in broth containing $100 \mu \mathrm{g}$. cephalothin $/ \mathrm{ml}$. when tested with a small inoculum suggesting a high intrinsic resistance; the exception was the strain of Enterobacter aerogenes. Small inocula of this organism did not grow in $100 \mu \mathrm{g}$. cephalothin $/ \mathrm{ml}$., whereas large inocula did. This type of response to cephalothin is similar to that of some penicillinase-producing strains of Proteus and Aerobacter which had little intrinsic resistance to ampicillin but which were resistant by virtue of their penicillinase formation when tested with a large inoculum (Sutherland, 1964). It should be emphasized that naturally occurring cephalothin-resistant strains differ in their cephalosporinase activity from strains made resistant in vitro by subculture on plates containing cephaloridine. The habituated strains although equally resistant to cephalothin showed no greater cephalosporinase activity than did sensitive strains (Barber \& Waterworth, 1964).

Until recently the penicillinases of Gram-negative bacteria have not been regarded as inducible enzymes, but it is now clear that there are exceptions to this. Induction of penicillinase activity has been demonstrated in a strain of Proteus morganii (Hamilton-Miller, 1964), that of cephalosporinase activity in a strain of Pseudomonas aeruginosa (Jago, Migliacci \& Abraham, 1963) and that of both in Proteus species (Ayliffe, 1964). The present investigation shows that penicillinase and cephalosporinase activity may also be induced in other Gram-negative species, but with some strains induction of these enzymes was not obtained even with high concentrations of potential inducers. Different antibiotics differ in their effectiveness as inducers of cephalosporinase activity. Benzylpenicillin, cephalothin and 6-aminopenicillanic acid were effective inducers, but the other antibiotics showed variable effects. Methicillin and cloxacillin are good inducers of staphylococcal penicillinase (Smith, Hamilton-Miller \& Knox, 1962). In the present investigation methicillin and to a lesser degree cloxacillin were found to be effective inducers of the cephalosporinase activity of 1 of $\mathbf{2}$ strains of $\boldsymbol{P}$. morganii (strain $\mathbf{1}$ ) and a strain of $\boldsymbol{P}$. vulgaris 
but not that of three other organisms tested, including a second strain of $\boldsymbol{P}$. morganii. Quinacillin is a poor inducer of staphylococcal penicillinase (Richards, Housley \& Spooner, 1963); in the present study it was found to induce the cephalosporinase activity of strain 1 of $\boldsymbol{P}$. morganii, but not that of the four other organisms tested. The difference obtained with methicillin, quinacillin and cloxacillin in the 2 strains of $\boldsymbol{P}$. morganii indicates that the effectiveness of these penicillins cannot be predicted even with the same species. Methicillin and cloxacillin have been found to inhibit penicillinase in several Gram-negative species (Hamilton-Miller \& Smith, 1964; Sutherland \& Batchelor, 1964) and cephalosporinase in Pseudomonas aeruginosa (Jago et al. 1963). In the experiments reported in this paper, partial inhibition of cephalosporinase activity occurred when one of the strains of $\boldsymbol{P}$. morganii and the strain of Enterobacter aerogenes were grown in the presence of cloxacillin.

I wish to thank Professor Mary Barber, Dr M. Richmond and Dr E. J. L. Lowbury for their advice and criticism, Beecham Research Laboratories Ltd. for a research grant and supplies of penicillins, Boots Pure Drug Co. Ltd. for supplying quinacillin and Glaxo Laboratories Ltd. for cephalothin.

\section{REFERENCES}

Ayliffe, G. A. J. (1963). Ampicillin inactivation and sensitivity of coliform bacilli. J. gen. Microbiol. 30, 339.

AyLiffe, G. A. J. (1964). Induction of cephalosporinase and penicillinase in Proteus species. Nature, Lond. 201, 1032.

Barber, M. \& Waterworth, P. M. (1964). Penicillinase resistant penicillins and cephalosporins. Brit. med. $J$, ii, 344.

Chauvette, R. R., Flynn, E. H., Jackson, B. G., Lavagnino, E. R., Morin, R. B., Mueller, R. A., Pioch, R. P., Roeske, R. W., Ryan, C. W., Spencer, J. L. \& Van Heyningen, E. (1962). Chemistry of the cephalosporin antibiotics. ii. Preparation of a new class of antibiotics and the relation of structure to activity. J. Am. Chem. Soc. 84, 3401.

Cowan, S. T. \& STeEL, K. J. (1961). Diagnostic tables for the common medical bacteria. J. Hyg., Camb. 59, $35 \%$.

Crompton, B., Jago, M., Crawford, K., Newton, G. G. F. \& Abraham, E. P. (1962). Behaviour of some derivatives of 7 -aminocephalosporanic acid and 6-aminopenicillanic acid as substrates, inhibitors and inducers of penicillinases. Biochem. J. 83, 52.

Fleming, P. C., Goldner, M. \& Glass, D. G. (1963). Observations on the nature, distribution and significance of cephalosporinase. Lancet, i, 1399.

Hamilton-Miller, J. M. T. (1963). Inducible penicillinase in Proteus morganii. Biochem. Biophys. Res. Comm. 13, 43.

Hamilton-Mrller, J. M. T. \& Smith, J. T. (1964). Inhibition of penicillinase from Grampositive and Gram-negative bacteria by substrate analogues. Nature, Lond. 201, 999.

Jago, M., Migliacci, A., \& Abraham, E. P. (1963). Production of a cephalosporinase by Pseudomonas pyocyanea. Nature, Lond. 199, 375.

Muggleton, P. W., O'Callaghan, C. H. \& Stevens, W. K. (1964). Laboratory evaluation of a new antibiotic-cephaloridine (Ceporin). Brit. med. J. ii, 1234.

Percival, A., Brumfitt, W. \& de Louvors, J. (1963). The role of penicillinase in determining natural and acquired resistance of Gram-negative bacteria to penicillins. J. gen. Microbiol. 32, 77.

Perret, C. J. (1954). Iodometric assay of penicillinase. Nature, Lond. 174, 1012.

Richards, H. C., Housley, J. R., \& Spooner, D. F. (1963). Quinacillin: A new penicillin with unusual properties. Nature, Lond. 199, 354 . 
Smith, J. T. \& Hamilton-Miller, J. M. T. (1963). Difference between penicillinases from Gram-positive and Gram-negative bacteria. Nature, Lond. 197, 976.

Smith, J. T., Hamilton-Minler, J. M. T. \& Knox, R. (1962). Isoxazolyl penicillins and penicillinase. Nature, Lond. 195, 1300.

SuTHERLAND, R. (1964). The nature of the insensitivity of Gram-negative bacteria towards penicillins. J. gen. Microbiol. 34, 85.

SutherLaND, R. \& Batchelor, F. R. (1964). Synergistic activity of penicillins against penicillinase-producing Gram-negative bacilli. Nature, Lond. 201, 868. 